\title{
NUEVAS APROXIMACIONES A LA HISTORIA URBANA DE ITAIIA: EL RENACIMIENTO TEMPRANO
}

por

\section{S. R. EPSTEIN}

London School of Economics and Political Science.

RESUMEN: La interpretación de la historia de la Baja Edad Media y la temprana Edad Moderna de Italia ba estado desde el siglo pasado fuertemente influida por la dicotomia norte-sur y los modelos centro-periferia. Este artículo desmonta los argumentos del dualismo a través de una caracterización de la crisis bajomedieval que destaca los factores de integración y a la vez de diferenciación regional en las economias europeas. A continuacion, realiza un exhaustivo recorrido por la dinámica de la urbanización de Italia entre finales del siglo XIV y comienzos del XVI para señalar la profunda transformación ocurrida en los ejes y las jerarquias urbanas en un periodo de descenso neto de la urbanizacion. La variable institucional se sitúa en el eje de los cambios y a su vez refleja en su variedad la fuerte diferenciación regional experimentada por Italia al bilo de la construcción de los Estados territoriales.

Palabras ClaVe: Urbanización. Instituciones. Mercados. Crisis siglo XIV. Italia. Edad Media. Edad Moderna. Regiones económicas. Relaciones campo-ciudad. Redes urbanas. Teoria centro-periferia.

ABSTRACT: Since the XIXth century, the interpretation of the bistory of the later Middle Ages and the Early Modern period in Italy bas been strongly influenced by north-south dichotomies and core-periphery models. This article undermines dualist arguments through an analysis of the late-medieval "crisis» which underlines the factors of integration at work, but also the development of regional differentiation in European economies. The text describes in detail the dynamics of urbanization of Italy between the late XIVth and the early XVI th centuries focusing on the transformation which occurred in urban networks and bierarbies in a period of stagnation in urbanization rates. Institutions are considered the main factor accounting for the changes in urban patterns, and its variety expresses the regional differentiation experienced by Italy along with the development of territorial States.

KFY wORDS: Urbanization. Institutions. Markets, Italy. Middle Ages Early Modern Period. Town-country relations. Economic regions. Urban networks. Core-periphery theory. XIV-century crisis 
A lo largo del siglo pasado, la historia de la Italia premoderna y de las ciudades italianas ha sido escrita como una historia de dos contrarios: como un contraste institucional entre gobiernos comunitarios (posteriormente republicanos) del norte, y regímenes señoriales, principescos y monárquicos; y como un contraste económico entre ciudades avanzadas, «burguesas», y áreas rurales de subsistencia, atrasadas, «feudales». Como atestiguan tanto la mitografía racista de la Liga Lombarda cuanto proclamas intelectualmente más ambiciosas sobre los efectos del «feudalismo» meridional sobte la «conciencia cívica» del presente ${ }^{1}$, este dualismo epistemológico ${ }^{2}$ está profundamente asentado y cargado emocional y políticamente.

Durante mucho tiempo, la identificación de la libertad comunal medieval con el nacionalismo decimonónico, y la supuesta conexión entre el éxito económico de las comunas en los siglos XIII y XIV y la superioridad industrial del norte de Italia en el XIX, hizo inusualmente complicada la tarea de los historiadores económicos. En Italia, la habitual actividad de contar la historia de la industrialización quedó inextricablemente entretejida con la necesidad de explicar la actual divisoria económica, social e institucional entre el Norte y el Sur, la llamada questione meridionale. A pesar de que las Grandes Narrativas del siglo XIX proporcionaban modelos prefabricados e implícitamente moralistas para ambos propósitos, también hacían posible eludir cualquier pregunta demasiado incisiva sobre la relación entre las estructuras institucionales de la Italia premoderna y su evolución económica a largo plazo. Hasta hace muy poco, por consiguiente, la interpretación dominante sobre la historia económica de Italia estaba basada en dos axiomas superpuestos: primero, que el desarrollo económico preindustrial surgió de las actividades dinámicas y orientadas por el beneficio por parte de emprendedores «burgueses» urbanos cuya misión histórica fue la de disolver las instituciones arcaicas, "feudales», del campo; y segundo, que fuertes poderes institucionales urbanos sobre el contado rural fueron un prerrequisito necesario para el crecimiento económico de larga duración. De ello se seguía que las ciudades-estado y las repúblicas urbanas del Norte tipifi-

1 PUTNAM, R. D., LEONARDI, R. y NANETTI, R. Y., Making democray work. Civic traditions in Modern Italy, Cambridge (Mass.), 1993.

2 Expresado de forma caracteristicamente lúcida en dos ensayos fundamentales de PHILP JONES, «La storia economica. Dalla caduta del'Impeto romano al secolo XIV", en ROMANO, R. y VIVANTI, C. (eds.), Storia d'Italia, Torino, 1974, vol. 2, págs. 1467-1810 y «Economia e società nell'Italia medievale: la leggenda della boxghesia», en ROMANO, R. y VIVANTI, C. (eds.), Storia d'Italia. Annali: La transizione del fexdalesimo al capitalismo, Torino, 1978, págs. 185-372. La tibia recepción de Jones en Italia se debió a dos malentendidos: en primer lugar, que sus ensayos contenían propuestas contradictorias, cuando de hecho trataban de complementarse mutuamente; y en segundo lugar, que su dualismo epistemológico era ajeno a la historiografia italiana, cuando en realidad sus trabajos se han convertido con el tiempo en referencia obligada. Véase también mi "Dualismo economico, pluralismo istituzionale in Italia nel Rinascimento», Revista d'bistòria medieval, 6, 1995, págs. 63-78.

Hispania, LVIII/2, nưm. 199 (1998) 417-438 
caban el «progreso» institucional y económico, que las monarquías papales y feudales del Centro y el Sur epitomizaban el «atraso», y que las raices de las divisiones sociales y económicas nacionales de la actualidad debían ser rastreadas en la Edad Media. El modelo puede ser dibujado gráficamente como sigue, de manera que la sección superior izquierda representa las regiones política y económicamente más dinámicas, y la sección inferior derecha contiene las más conservadoras y atrasadas.

TABLA 1. UN MODELO DE INTERACCIÓN INSTITUCIONAL Y ECONÓMICA

\begin{tabular}{||l|l|l|}
\hline & \multicolumn{1}{|c|}{ Poder comunal } & \multicolumn{1}{c|}{ Poder señorial } \\
\hline $\begin{array}{l}\text { Economía centrada en la } \\
\text { ciudad }\end{array}$ & $\begin{array}{l}\text { Florencia, Venecia, Génova y } \\
\text { sus regiones }\end{array}$ & $\begin{array}{l}\text { Lombardia, ¿Emilia- } \\
\text { Romagna? }\end{array}$ \\
\hline $\begin{array}{l}\text { Economía centrada en el } \\
\text { campo }\end{array}$ & $\begin{array}{l}\text { Italia Central (Umbria, } \\
\text { las Marcas, Lazio) }\end{array}$ & Italia Meridional \\
\hline
\end{tabular}

Esta tradición historiográfica alcanzó su plenitud en dos análisis magistrales de Philip Jones y Maurice Aymard sobre la transición del feudalismo al capitalismo ${ }^{3}$. La cuestión que se les hizo abordar en ellos fue la siguiente: ¿Por qué si la Italia central-septentrional se hallaba tan avanzada durante el Renacimiento temprano, no tuvo lugar una transición temprana del feudalismo al capitalismo? ¿Por qué a partir del 1500 el país experimentó un relativo declive económico? ¿Por qué se industralizó tardíamente Italia?

En superficie, Jones y Aymard dieron soluciones bastante diferentes al enigma, marcadas por sus distintas perspectivas cronológicas. Jones, un medievalista, abordó la cuestión proclamando que el capitalismo comercial era una «leyenda», una fina pátina extendida sobre un soporte cultural y social feudal que aquél nunca consiguió verdaderamente socavar. La sociedad urbana itálica era, en su núcleo, una forma transfigurada de señorialismo. Jones vino a decir que la cuestión entera de la «transición frustrada» al capitalismo de la Italia del Renacimiento estaba basada en la falsa premisa de que las precondiciones sociales e institucionales de la transición se hallaban ya presentes a la altura de 1400 .

Aymard, modernista, siguió una línea argumental inspirada en Braudel y Wallerstein, la cual de hecho enfatizaba los rasgos avanzados, «capitalistas», de las comunidades aventajadas de Florencia, Venecia, Milán y Génova. Para Aymard, sin embargo, el problema del capitalismo comercial italiano residia en el hecho de que estaba basado en relaciones de explotación. Esta situación sembró según él la semilla de su propia destrucción. Los beneficios mercatiles pro-

3 JONES, P., «EConomia e società...op. cit.»; AYMARD, M., «La transizione del feudalesimo al capitalismo", en ROMANO y VivaNTt, (edis.), Storia d'Ttalia. Annali 1...op. cit., págs. 1131-1192. 
cedian de la explotación por parte de las ciudades del norte de sus hinterlands inmediatos, el contado, por medio del ejercicio de la jurisdicción superior, y sobre la explotación por parte de la Italia del Norte del Mezzogiorno, a través del intercambio desigual de las manufacturas septentrionales (principalmente textiles) por materias primas y productos agrícolas meridionales. La desincentivación a largo plażo de la innovación impuesta por dichas relaciones explica la "transición fallida» del país (transizzione in bianco) al capitalismo.

A pesar de las diferencias sustanciales en énfasis e interpretación, los argumentos de Jones y Aymard compartían en realidad tres rasgos esenciales. En primer lugar, ambos se dedicaban a explicar el supuesto atraso económico del país, que era definido como la incapacidad de industrializarse. En segundo lugar, los dos asumían que las causas del fracaso eran institucionales, y que se encontraban en el carácter no burgués de la tradición comunal urbana del norte de Italia, y que los orígenes cronológicos del declive relativo se hallaban en la Baja Edad Media, cuando las comunas independientes fueron subsumidas en estados regionales más grandes. En tercer lugar, ambos subrayaban la divisoria institucional del país por líneas Norte-Sur, bajo condiciones dominadas en el Norte por la explotación de la ciudad sobre el campo, y condiciones en el Sur caracterizadas por ciudades débiles y formas de cultivo extensivas "feudales».

Ambas contribuciones presentaban por consiguiente argumentos negativos. Reafirmaban el moralismo implícito de interpretaciones previas, en las cuales el fracaso italiano se vinculaba a la ausencia de una verdadera revolución burguesa. Reconfirmaban las duradexas dicotomías entre campo y ciudad y entre Italia septentrional e Italia meridional. Por último, presumían que la Italia premoderna podía ser analizada como un "sistema» económicamente unificado dotado de una división del trabajo regional claramente definida.

Aunque estos argumentos parecian subrayar la importancia de los factores institucionales, en realidad reducían las diferencias institucionales del país a una serie de burdas simplificaciones, y cortocircuitaban cualquier comprensión clara de cómo las estructuras institucionales influían en la dinámica económica. Ignoraban el carácter profundamente regional de la economía premoderna, que se demuestra en el hecho de que un mercado nacional unificado sólo fue establecido después de la unificación política del siglo XIX ${ }^{4}$. En relación con la historia urbana, la distinción entre funciones económicas e institucionales de las ciudades no fue nunca establecida con claridad, lo cual llevó a la confusa asurición de que los poderes políticos fuertes eran tanto un prerrequisito pata el crecimiento urbano sostenido cuanto la causa del subsiguiente declive económico de Italia.

En este artículo propongo que para salir de este impasse teórico debemos prestar más atención al papel de las instituciones en el crecimiento económico. En particular, es necesaria una mejor comprensión de los efectos distributivos y redistributivos de los gobiernos premodernos y de cómo las estructuras mercan-

4 SERENI, E., «Mercato nazionale e accumulazione capitalistica nell'Unità italiana», Studi Storiá, 1, 1959-60, págs. 513-568.

Hispania, LVII/2, num. 199 (1998) 417-438 
tiles y fiscales influian sobre los incentivos económicos. En otras palabras, debemos comprender la economía política de los mercados premodernos. Esto requiere un enfoque que es a la vez comparativo en ámbito y regional en escala: lo primero, porque los ejemplos contrafactuales producidos por el enfoque comparativo nos acercan a lo más parecido a un experimento histórico controlado; y lo segundo porque era principalmente en el nivel de la región, y no del estado-nacional, donde las estructuras administrativas y los desarrollos económicos premodernos interactuaban con mayor fuerza y producían los efectos más profundos ${ }^{5}$.

Trabajos recientes sobre la Italia y la Europa bajomedievales dan algunas pistas sobre cómo podría funcionar en la práctica este enfoque combinado. En otra parte he argumentado que la "crisis" bajomedieval se comprende mejor si se entiende como una "crisis de integración»" ${ }^{6}$. Existe una creciente evidencia que sugiere que la «crisis» no fue causada por la presión de la población sobre los recursos en una economía tecnológicamente estancada, tal y como argumentaban los historiadores económicos neomalthusianos, pues la tecnología que podía haber elevado 1 a producción se hallaba en realidad disponible y se aplicaba de hecho con éxito en varias regiones. La respuesta a la cuestión de por qué las técnicas más productivas no se adoptaron más difusamente es tal vez que, en la mayor parte de las regiones, la parcelización jurisdiccional que se encontraba en el corazón del entramado político feudal elevaba los costes de transacción por encima del nivel sobre el que resultaba económicamente beneficioso emplear tecnología más productiva.

Desde esta perspectiva, la Peste Negra se revela como un fenómeno exógeno que exacerbó dificultades económicas ya existentes, mientras que la "crisis» bajomedieval emerge como una lucha más amplia sobre las consecuencias económicas y políticas de la parcelización feudal del poder. La pugna afectó a señores feudales $y$, en casos como el norte-centro de Italia, a poderosas elites urbanas cuyos intereses se hallaban vinculadas al status quo, contra alianzas circunstanciales y cambiantes de campesinos, comunidades rurales y estados centralizadores cuyo objetivo colectivo era reducir las prerrogativas económicas y fiscales de los anteriores, bien fuera eludiéndolas bien incorporándolas a jurisdicciones más extensas. A pesar de que las diferencias institucionales y económicas iniciales produjeron toda una variedad de resultados en estos conflictos regionales, tuvo lugar también en gran medida un más importante proceso de convergencia institucional, de manera que a la altura de comienzos del siglo XVI era posible distinguir por toda Europa occidental una pauta común de integración jutisdiccional impulsada por el crecimiento estatal.

Desde este punto de vista, la consecuencia económica más relevante de la «crisis» fue la disminución de los costes de los intercambios y el aumento de la in-

5 PRAK, M., "Le tegioni nella prima età moderna», Proposte e ricerche: Economia e società nella storia dellTtalia centrale, 35, 1995, págs. 7-40.

6 EPSTEIN, S. R., «The late medieval crisis as an "Integration crisis") en 4ème Journées Braudekiennes, Nijmegen, 23-24 de mayo, 1997 (Mexico D.F., 1998).

Hippunia, LVIIK/2, núm. 199 (1998) 417-438 
tegración de los mercados a escala regional. El efecto de la integración estatal sobre las ciudades fue doble. Por un lado, la competencia ( $y$ por tanto la influencia mutua) aumentó entre ciudades fisicamente adyacentes y produjo «jerarquías» urbanas más nítidamente definidas, en las que el tamaño de la ciudad y su posición venían determinadas por sus funciones económicas y, cada vez más, administrativas. La expresión más llamativa de estos cambios fue la invención de la capital políica. Por otro lado, las pautas de urbanización sugieren que, de la mano de la tendencia de las economías regionales a converger por toda Europa - -al comenzar países relativamente atrasados como Inglaterra a alcanzar a los demás y al entrar buena parte de Italia en una larga fase de declive relativo-, el proceso de crecimiento estatal inició también un proceso de diferenciación regional. Los distintos equilibrios de poder institucional que se alcanzaron entre los cuerpos soberanos (principes o, en el norte de Italia, elites urbanas dominantes), las elites urbanas y señores feudales, y las comunidades rurales durante la "crisis" bajomedieval, generaron oportunidades y constricciones divergentes en materia de especialización y comercio. Inevitablemente, los efectos de estos conflictos se dejaron sentir de forma particularmente fuerte en las economías urbanas.

Esta reinterpretación de los aspectos económicos de la «crisis» se halla en buena sintonia con el claro interés existente entre los historiadores italianos de los últimos años por la transición del commune al Estado territorial o regional. Tanto los historiadoress económicos como los institucionales han interpretado el fenómeno como un proceso de integración y han abordado la interacción entre factores institucionales y economicos a escala regional 7 . Ello ha estimulado a su vez un interés por el análisis comparativo y ha generado una creciente consciencia y comprensión de la variedad institucional de los estados italianos del Renacimiento ${ }^{8}$. El papel de las ciudades es especialmete debatido, así como las diferencias entre el Mezzogiomo y el Norte. ${ }^{9}$

Mi intención es seguir esta línea centrándome en dos temas de central relevancia dentro de los debates actuales: las estructuras de urbanización y las je-

7 FASANO GUARINI, E., "Centro e periferia, accentramento e particolarismi: dicotomia o sostanza degli Stati in età modernay, en CHITOLINI, G.; MOLHO, A. y SCHIERA, P. (eds.), Origini dello Stato. Processi di formazione statale in Italia fra medioevo e età moderna, Bolonia, 1984, págs. 147. 176; VARANINI, G. M., Comuni cittadini e stato regionale. Ricerche sulla Terraferma veneta, Verona, 1992; EPSTEIN, S. R., «Storia economica e storia istituzionale dello stato", en CHrI'OLINI, MOLHO y SCHIERA, Origini dello stato...op. cit., págs. 97-111.

8 CHITTOLINI, G., «Organizzazione territoriale e distretti urbani nell'Italia del tardo medioevo" en CIITTOLINI, G. y WILLOWEIT, D. (eds.), L'organizzazione del territorio in Italia e Ger. mania: secoli XIII.XIV, Bologna, 1994, págs. 7-26; VARANINI, G. M., «L'organizzazione del distretto cittadino nell'Italia padana dei secoli XIIJ-XIV (Matca Trevigiana, Lombardia, Emilia)» Ibidem., págs. 133-233; idem, «Modelli urbani e modelli principeschi di organizzazione del territorio nell'Italia del Quattrocentom en CHITTOLINI, G. (ed.), Principi e città alla fine del Medioevo, San Miniato, 1997, GINATEMPO, M., "Gerarchie demiche e sistemi urbani nell'Italia bassomedievale: una discussione», Società e storia, 72, 1996, págs. 347-383.

9 GINATEMPO, M., «Le città italiane, XIV.XV secolo», en 23 Semana de estudios medievales. Poderes públicos en la Europa Medieval: Principados, Reinos y Coronas, Estella, 1997, págs. 149-209.

Hipania, LVIII/2, núm. 199 (1998) 417-438 
rarquias urbanas. Mi argumento es que, en gran medida, las estructuras urbanas convergieron a lo largo de la Italia bajomedieval hacia una pauta regional común. Las jerarquías urbanas se hicieron más pronunciadas, al elevar la formación estatal las fortunas de las capitales regionales y al hundir las de sus fracasados competidores. Las tasas medias de urbanización se mantuvieron mury elevadas dentro de la norma europea, pero no se elevaron muy por encima de los niveles alcanzados antes de la Peste Negra; puede que incluso experimentaran cierto declive. Por otra parte, la "crisis» bajomedieval creó también importantes discrepancias estructurales entre regiones, y dio al sistema urbano en su conjunto la forma que mantendría prácticamente inalterada hasta la Revolución Industrial. Estos desartollos fueron el resultado de una interacción entre reajustes políticos internos y el acceso a mercados internacionales, los cuales dieron a unas pocas ciudades la oportunidad de extender su átea de influencia y a Italia en conjunto su singular pauta urbana de «primacía descentralizadas. Por contra, las diferencias institucionales entre ciudades anteriores a la peste bubónica en la Italia central y septentrional y en el sur desempeñaron un papel comparativamente menor en los desarrollos posteriores.

II

En el cénit de la expansión urbana y comercial de comienzos del siglo XIV, la península itálica había logrado la tasa de urbanización más elevada con mucha diferencia de los países europeos. La diferencia era tan grande que estudios recientes de la urbanización medieval italiana han situado en cinco mil habitantes el umbral de lo que se considera urbano, un tamaño que en la mayor parte de los demás países definía una ciudad de gran tamaño ${ }^{10}$. Sobre este nivel inferior de medida, Italia contaba con 129 centros con poblaciones entre cinco y diez mil habitantes, 74 ciudades entre diez y cuarenta mil, una docena de metrópolis por encima de los cuarenta mil habitantes y posiblemente 4 megalópolis (el estatus de Génova no está del todo claro) de más de ochenta mil habitantes (Tabla 2). Por contextualizar estas cifras, Russell ha estimado que Europa en su conjunto exclayendo Italia contaba con 95 ciudades por encima de los diez mil habitantes, incluyendo 8 de más de cuarenta mil y sólamente una megalópolis, París, por encima de los ochenta mil ${ }^{11}$. En la práctica, la Italia de comienzos del siglo XIV parece haber poseido casi tantas ciudades por encima de diez mil habitantes como el resto de Europa en su conjunto.

\section{Ibidem.}

11 RUSSELJ, J. C., Medieval Regions and tbeir cities, Newton Abbott, 1972. Aunque estas estimaciones puedan parecer demasiado bajas, el principal error de Russell tiene que ver en realidad con Italia, para la cual él cuenta sólo 30 ciudades entre diez y cuarenta mil habitantes; es poco probable que similares subestimaciones se produzcan también para las restantes y menos urbanizadas regiones europeas. 
Tabia 2. POBlación URbaNa EN ITALia, PoR TAMaÑo, C. 1300-C. 1500 (NÚMERO DE CIUDADES Y PORCENTAJES)

\begin{tabular}{|l|l|l|l|}
\hline & $\begin{array}{c}\text { Fines siglo XIU- } \\
\text { comienzos siglo XIV }\end{array}$ & Comienzos siglo XV & \multicolumn{1}{|c|}{$\begin{array}{c}\text { Fines siglo XV- } \\
\text { comienzos siglo XVI }\end{array}$} \\
\hline 80.000 & $4(1.9)$ & $2(2.0)$ & $3(2.0)$ \\
\hline $40.000-79.000$ & $8(3.7)$ & $1(1.0)$ & $10(6.6)$ \\
\hline $20.000-39.000$ & $12(5.6)$ & $11(11.2)$ & $8(5.3)$ \\
\hline $10.000-19.000$ & $62(28.8)$ & $10(10.2)$ & $29(19.2)$ \\
\hline $5.000-9.000$ & $29(60.0)$ & $74(75.5)$ & $101(66.9)$ \\
\hline Total & $215(100)$ & $98(100)$ & $151(100)$ \\
\hline
\end{tabular}

Fuentes: Ginatempo, M. y Sandri, L. L'7lalia delle cittz. Il popolamento urbano tra Medioevo e Rinascimento (secolt XIII-XVI), Florencia, 1990; Epstein, S. R. Ant island for itself. Economic development and social change in late Medieval Siciby, Cambridge, 1992, cap. 2 (para Sicilia); Sakellariou, E. The Kingdom of Naples under aragonese and spanish rule. Population growth and economic and social evolution in late ffieenth and early sixteenth centuries, Ph.D., Faculty of History, University of Cambridge, 1996, cap. 2 (para Nápoles).

El rasgo más llamativo de la urbanización italiana en este período es el hecho de que no quedó restringida a las regiones al norte de Roma. A pesar de la ausencia de un centro hegemónico regional fuerte -Nápoles se hallaba aún por debajo de los cuarenta mil habitantes, y su espectacular crecimiento se hallaba aún a siglo y medio de distancia - la tasa de urbanización anterior a la peste en el Reino de Nápoles, casi un 30 por ciento, era extraordinariamente elevada dentro de la media europea (Tabla 3). Una medición más moderada, conocida como el «índice urbano», basada en las diez ciudades más grandes, produce una cifra justo por debajo del 12 por ciento; la menor de estas ciudades italianas meridionales tenía una población entre doce mil y quince mil habitantes (Tabla 4). Según las (claramente cuestionables) estimaciones de Russell, esta cifra sitúa el Reino de Nápoles entre las siete regiones más urbanizadas de Europa, si bien con un porcentaje urbano sustancialmente inferior al de las regiones de Milán, Venecia y Florencia ${ }^{12}$.

Tal vez la evidencia más sorprendente tiene que ver con Sicilia (Tabla 4), que poseía el índice urbano más desconcertante, por encima del 40 por ciento. Aunque ello pueda deberse a la naturaleza de la evidencia (basada en una fuente relacionada con una imposición fiscal que posiblemente golpeaba con más fuerza a las ciudades más grandes y ricas y por consiguiente sobrestima el grado de concentración urbana), fuentes posteriores más fiables confirman que la Sicilia medieval y de la primera Edad Moderna tenía una de las tasas de urbani-

12 Ibidem., pág. 235.

Hippania, LVIII/2, num. 199 (1998) 417-438 
zación más elevadas de todas las regiones europeas, equiparable, o incluso superior, a la de las regiones más urbanizadas del Norte.

TABLA 3. URBANIZACIÓN EN EL REINO DE NÁPOLES, C. 1300-C. 1550

\begin{tabular}{||l|c|c|c|c||}
\hline & $\mathbf{1 3 2 0}$ & $\mathbf{1 4 4 7}$ & $\mathbf{1 5 0 8}$ & $\mathbf{1 5 3 2}$ \\
\hline $\begin{array}{l}\text { Terra di Lavoro } \\
\text { (con Molise) }\end{array}$ & 31,2 & 39,1 & 44,8 & 57,6 \\
\hline Terra di Bari & 81,8 & 11,9 & 29,9 & 42,1 \\
\hline Terra d'Otranto & 51,4 & 12,9 & 22,9 & 30,0 \\
\hline Basilicata & 18,7 & 0 & 0 & 0 \\
\hline Calabria Citra & 17,6 & 0 & 0 & 8,0 \\
\hline Calabria Ultra & 23,9 & 8,1 & 9,5 & 21,9 \\
\hline Capitanata & 28,6 & 0 & 0 & 0 \\
\hline Principato Citra & 24,2 & 5,8 & 23,5 & 23,7 \\
\hline Principato Ultra & 0 & 0 & 0 & 5,8 \\
\hline Abruzzo Citra & 0 & 0 & 0 & 6,6 \\
\hline Abruzzo Citra & 0 & 25,6 & 20,8 & 36,6 \\
\hline Total & 28,8 & 14,4 & 20,2 & 29,4 \\
\hline
\end{tabular}

Fuente: Sakellariou, The kingdom of Naptes, cap. 2. La urbanización está definida como la proporción de habitantes en asentamientos de más de cinco mil habitantes.

TABLA 4. INDICES URBANOS EN ITALIA, C. 1300-C. 1550

\begin{tabular}{|l|c|c|c|c|}
\hline & $\begin{array}{c}\text { Fines del siglo } \\
\text { XIII-Comienzos } \\
\text { del siglo Xav }\end{array}$ & $\begin{array}{c}\text { Comienzos del } \\
\text { siglo XV }\end{array}$ & $\begin{array}{c}\text { Fines del siglo } \\
\text { XV }\end{array}$ & $\begin{array}{c}\text { Mediados del } \\
\text { siglo XVI }\end{array}$ \\
\hline Véneto & $23,4 ?$ & - & - & - \\
\hline Lombardía & $19,3 ?$ & - & - & - \\
\hline Toscana & 32,0 & 27,0 & - & 24,0 \\
\hline Nápoles & 11,7 & 13,6 & 16,3 & 22,3 \\
\hline Sicilia & 47,8 & 29,8 & 34,1 & 30,4 \\
\hline
\end{tabular}

Fuentes: Russell, Medieval Regions..., pag. 235 (Véneto y Lombardía); Epstein, S. R. «Cities, regions and the Late Medieval crisis: Sicily and Tuscany compareds, Past er Present, 130, 1991, pp. 3-50 (Toscana); Sakellariou, The Kingdom of Naples..., cap. 2 (Nápoles); Epstein, An island..., cap. 2 (Sicilia). El índice urbano mide la proporción de habitantes residentes en las diez ciudades de mayor tamano. 
Detrás de esta efervescencia urbana anterior a la Peste Negra, extraordinaria y sin precedentes, es posible discernir varias pautas regionales definidas. En primer lugat se hallaban tegiones con una elevada tasa de urbanización (posiblemente por encima del 30 por ciento) y con cabezas regionales fuertes. De éstas había tres: una macro-región putativa centrada en el valle del Po, con vértices en Venecia, Milán y Génova rodeadas por una nebulosa de ciudades por encima de los cuarenta mil habitantes; Toscana, con vértices en Florencia, Pisa y Siena; y Sicilia, con Palermo y Messina como líderes urbanos. Después venían áreas con elevadas tasas de urbanización en la línea del 20-30 por ciento, y cabezas regionales más débiles: Piamonte, con centros regionales en competencia en Alessandria, Asti y Chieri; las regiones italianas centrales de Romagna, las Marcas, Umbria y el Lazio, con centros regionales en Bolonia, Ancona, Perugia y Roma; y el Reino de Nápoles, con centros hegemónicos regionales en Nápoles, Salerno y Aversa en la costa oeste, Melfi y Lucera en el interior, y Taranto, Brindisi, Monopoli, Barletta, Bari, Bitonto y Trani en la costa oriental. Por último, se encuentran regiones geográficamente periféricas con niveles de urbanización más bajos e incluso jerarquías urbanas más débiles, por ejemplo en Friuli, Trentino y Cerdeña.

Uno de los rasgos más relevantes de estas estructuras urbanas es la ausencia de jerarquias regionales fuertes. Pocas ciudades tenían una ventaja regional clara, las mayor parte de las regiones contenian varias ciudades en competencia por el liderazgo. Esto se refleja en el rasgo más característico de la urbanización anterior a la Peste Negra, el gran número - por encima de 60 - de asentamientos de rango medio entre diez y veinte mil habitantes (Tabla 2). Su elevado número sugiere también que la competencia entre ellas era relativamente débil, y que sus funciones como «ugares centrales» para un mercado interior eran ejercidas principalmente sobre su hinterland inmediato más que a nivel regional. Esta impresión gana crédito con la observación de que las únicas ciudades que descollaban plenamente por encima de las demás, es decir, Venecia, Milán, Génova y Florencia, eran también las que habían más satisfactoriamente toto estas limitaciones de sus mercados interiores para establecer un sólido puente con el comercio y la banca internacional. Bajo condiciones de escasa integración económica y política a nivel regional, la explotación de los mercados extranjeros podía, paradójicamente, haber resultado más fácil (al ofrecer costes de transacción menores) que el comercio en mercados "domésticos» para las ciudades capaces de incorporarse a aquéllos. Dadas las circunstancias predominantes antes de la Peste Negra, el auge del éxito metropolitano estaba basado más en un comportamiento como nódulo redistributivo crítico dentro de una red urbana de larga distancia que en la adopción de funciones organizativas propias de una ciudad hegemónica en una región integrada ${ }^{13}$.

13 HOHEMBERG, P. M. y LEES, L. H., The making of wrban Europe, 1000-1950, Londres, 1985 , subrayan la dialéctica entre funciones jerárquicas y funciones nodales de las ciudades.

[Jispania, LVIH/2, núm. 199 (1998) 417-438 
No resulta sorprendente que unas pérdidas demográficas en el campo situadas entre el 50 y el 70 por ciento en el siglo posterior a la Peste Negra no dejaran intactas las ciudades. A comienzos del siglo XV el número de asentamientos urbanos por encima de cinco mil habitantes había caído en más de la mitad (Tabla 2). La disrupción del comercio causada por la elevada mortalidad, los grandes flujos migratorios y la actividad militar virtualmente ininterrumpida parece haber golpeado a las ciudades de manera particularmente negativa, tanto que entre 1350 y 1450 la proporción de habitantes urbanos de hecho disminuyó ${ }^{14}$. Estos efectos fueron sin embargo transitorios y rápidamente subsanados. A la altura de comienzos del siglo XVI la población había estado creciendo durante medio siglo y en vatias regiones se estaba aproximando al nivel anterior a la peste, de manera que los efectos estructurales de la "crisis» podían ser claramente discernidos para entonces. Las estructuras urbanas posteriores a la Peste Negra eran diferentes de las anteriores a 1300 en tres aspectos significativos: primero, la urbanización tecuperó los niveles antetiores a la peste, pero el número total de ciudades disminuyó abruptamente; segundo, las estructuras urbanas se tornaron más polarizadas y jerarquizadas; tercero, las pautas regionales se hicieron más variadas. Conviene discutir cada uno de estos puntos por separado.

1. A comienzos del siglo XVI las tasas de urbanización parecen haber recuperado la mayor parte de sus pérdidas desde la Peste Negra. Esto muestra una pauta distinta de la descrita por Jan de Vries, quien sugiere a partir de datos de comienzos del siglo XIV publicados por Russell y Génicot que hacia 1500 la urbanización se habia incrementado de forma sustancial por toda Europa occidental ${ }^{15}$. Ciertamente, la afirmación de de Vries debe ser puntualizada en dos sentidos. Primero, tanto Génicot como Russell subestiman la población urbana a la altura de 1300; de Vries admite esto con respecto a Génicot, pero parece tomar las estimaciones de Russell como fiables, lo cual está lejos de ser el caso ${ }^{16}$. No obstante, las diferencias observadas por de Vries - quien estima que la población urbana en 1300 era alrededor de un 85 por ciento la de 1500 , con una población total en 1300 substancialmente superior- parecen demasiado grandes para ser simplemente desechadas como un error estadístico.

$14 \mathrm{Al}$ menos es lo que parece suceder en las regiones para las que hay evidencia. Para Sicilia, EPSTEIN, An island..., caps. 2-3; para NAPOLES, SAKELLARIOU, Tbe Kingdom of Naples... cap. 2; para Toscana, EPSTEIN, «Cities, Regions...». El virtual colapso del régimen Visconti a comienzos del siglo XV vino también probablemente acompañado de un tipo similar de crisis urbana en Milán.

15 DE VRIES, J, European urbanization, 1500-1800, London, 1984, págs. 41-43, basándose en RUSSELL, Medieval Regions..., y GÉNICOT, L., «Les grands villes d'Occident en 1300», en É $c 0-$ nomies et sociêtés au Moyen Age. Mélanges offerts à Edouard Perroy, París, 1973, págs. 199-219.

16 Véase más arriba, nota 11 .

Hi.punia, LVIII/2, núm. 199 (1998) 417-438 
En segundo lugar, la diferencia entre mis estimaciones y las de de Vries podría ser achacada al empleo de diferentes métodos de recogida de datos. Desde el momento en que de Vries adopta un umbral urbano de diez mil y yo empleo un umbral inferior, cinco mil habitantes, los efectos de la mayor concentración en ciudades por encima de los diez mil habitantes aparecerían como un aumento de la urbanización según los criterios de de Vries, pero no según los míos. Sin embargo, en la Italia bajomedieval sucedió precisamente lo contrario. Aunque tanto en mis criterios como en los de de Vries el número de ciudades era significativamente inferior en 1500 respecto a 1300, disminuyendo bien de 207 a 151 (un 27 por ciento menos) o de 86 a 50 (un 42 por ciento menos) en función de la medida de urbanización empleada (Tabla 2), la proporción de ciudades entre cinco y diez mil habitantes de hecho aumentó de un 60 a un 67 por ciento, señalando que en el nivel inferior de las jerarquías urbanas estaba teniendo lugat un proceso de descentralización más que una concentración tal y como sugiere de Vries que ocurrió en Europa occidental en su conjunto.

En suma, toda una sólida evidencia circunstancial indica que las tasas de urbanización en Italia no aumentaron como un efecto de la "crisis", mientras que sí lo hicieron en el resto del continente. Italia parece haber alcanzado una meseta urbana que no seria significativamente sobrepasada antes del siglo XIX ${ }^{17}$.

2. Ello no significa que nada cambiara entre 1300 y 1500 , sino tan sólo que los cambios más importantes habtían de tener lugar en las funciones urbanas más que en el tamaño general de las ciudades. El segundo gran efecto de la "crisis» consistió en la alteración de la disposición de las ciudades dentro de las jerarquías regionales, de manera que ya a la altura de 1500 la estructura urbana había quedado mucho más polarizada (Tabla 2). Al lado del crecimiento porcentual de ciudades entre cinco y diez mil habitantes, se encuentra un mayor aumento (del 11 al 14 por ciento) en el número de ciudades grandes con más de veinte mil habitantes, ciudades que podían ser tazonablemente denominadas centros regionales. Consecuentemente, el porcentaje de ciudades de rango medio (con poblaciones entre diez y veinte mil) se redujo drásticamente en una tercera parte.

Uno de los aspectos más interesantes de estos cambios es la creciente concentración en los niveles superiores de la jerarquía urbana. Esta concentración. se caracterizaba por tres rasgos relevantes. En primer lugar, la cima superior de la jerarquía todavía incluía a Milán y Venecia, pero Florencia y Génova habían sido degradadas a perpetuidad. Su declive fue compensado por el extraordinario crecimiento de Nápoles, que estaba rápidamente pasando de ser un asentamiento de segundo orden con funciones principalmente regionales a transformarse en una de las grandes metrópolis de la Edad Moderna. Unas décadas más tarde, a esta troika se sumaría Roma. El efecto de estos cambios fue el reemplazamiento de una estructura multipolar dominada por las metrópolis

17 DE VRIES, European urbanization..., pág. 39, tabla 3.7. De Vries probablemente subestima el nivel de urbanización de Italia, pero es más fiable en su tendencia durante la Edad Moderna.

Hiqpania, LVIII/2, núm. 199 (1998) 417-438 
comerciales del norte de Italia por una estructura geográficamente más equilibrada si bien aún multipolar.

En segundo lugar, la proporción de ciudades en el nivel de los cuarenta a ochenta mil habitantes casi se duplicó. Lo que según los estándares europeos eran aún consideradas metrópolis eran, según los estándares italianos, poco más que centros regionales. Sus funciones eran a veces políticas (Ferrara, Bolonia, Palermo, al principio Roma), otras veces más industriales y comerciales (Brescia, Cremona, Verona, Génova y Messina) y, en algunos casos, como el de Florencia, una combinación de las dos. Pero de lo que estas ciudades carecían de manera crucial en comparación con las grandes capitales suprarregionales era la combinación de un mercado interior amplio - que podía estar, pero no necesariamente (como prueba el ejemplo de Milán) bajo su control político o jurisdiccional directo, pero que en cualquier caso proporcionaba alimento para la población urbana en aumento- $y$ de acceso privilegiado a los mercados internacionales.

Las ciudades menores se especializaron bien como slugates centrales», organizando y redistribuyendo actividades económicas dentro de su hinterland inmediato, o bien actuaron como Génova y Messina principalmente como "vías de salida» para el comercio entre regiones y mercados más distantes. Estas ciudades compensaton la ausencia de una función con el teforzamiento de la otra, siendo incapaces de desarrollar ambas funciones hasta el máximo. Las ciudades grandes, por contra, encabezaban sistemas urbanos que incluían una potente dimensión interior y otra internacional fuerte: se proyectaban tanto hacia dentro como hacia fuera. Esto parece distinguirlas señaladamente de sus predecesoras anteriores a la "crisis». Entre los rasgos más señalados del crecimiento metropolitano en Italia antes de 1350 se hallaba la desconexión entre poder y rango. El principal fundamento de la singularidad de Génova, Florencia, Milán y Venecia antes de la peste no era la explotación políticamente establecida de su contado dependiente, pues éste era un rasgo que compartían virtualmente con todas las demás ciudades de la Italia central y septentrional. Lo que les otorgaba su marca distintiva era el disfrute, por medio de una combinación de habilidad, casualidad, agresividad y posición, de un papel dominante en más de una red de comercio e industria internacional. Ello prueba que en 1300 una megalópolis podía surgir de las olas del éxito comercial. Pero como atestigua el declive de Génova y Florencia, a la altura de 1500 esto no era ya suficiente.

De Vries ha argumentado que un rasgo distintivo de la Italia altomoderna eta la presencia de al menos dos o tal vez tres mactorregiones encabezadas respectivamente por Venecia, Nápoles y Roma ${ }^{18}$. Esta ausencia de primacía, que se hallaba ya establecida en el cambio hacia el siglo XVI, fue el resultado de una singular combinación de fragmentación política, que elevó las batreras al co-

18 Ibidem, págs. 109-112, donde Génova es identificada con otra capital suprarregional de un sistema urbano esencialmente exterior a Italia. Yo sugeriría sustituir Génova por Milán. 
mercio interior entre estados, y de la oportunidad de desempeñar un papel dominante en redes comerciales (Venecia), políticas (Nápoles) y religiosas (Roma) que trascendian los confines regionales e incluso nacionales.

El tercer rasgo importante de concentración urbana consiste en que las estructuras bajomedievales etan más jerárquicas que las anteriores a la peste, y además las jerarquías estaban tegionalmente definidas. Esto se refleja en el relativo declive de los centros de rango medio del centro-norte, que antes eran ciudades-estado independientes cuyas capacidades económicas y militares quedaron expuestas a una creciente competencia por lograr la hegemonía regional y resultaron insuficientes. Aunque los límites entre regiones urbanas no seguian precisamente líneas de frontera política, estas últimas comenzaton a desempeñar un papel cada vez más importante en la definición de las nuevas jerarquías urbanas, tanto al impedir el comercio y hasta cierto punto la movilidad personal, cuanto al magnificar los efectos de las distintas políticas fiscales sobre la distribución del poder y los recursos entre ciudades y entre el campo y la ciudad.

Esto apunta a los efectos de la formación estatal bajomedieval sobre el comercio y, a través de él, sobre la estructura urbana. Las consecuencias fueton dobles. En primer lugar, los estados deseaban clarificar sus fronteras para establecer más eficientemente su soberanía y los impuestos sobre el comercio exterior; el involuntario efecto secundario de esto fue la invención de la práctica social del contrabando (por ejemplo, sobre el comercio considerado ilegítimo por no estar sometido a impuestos). En segundo lugar y de mayor importancia, la extensión de la soberanía estatal redujo e incluso abolió las tarifas aduaneras sobte el comercio interior. Esto se llevó a cabo a través de la integración orgánica de territorios feudales o urbanos previamente independientes, como en los estados regionales de Florencia, Milán y Venecia; o por el rechazo en otras partes del derecho autoarrogado de los señores feudales y ciudades de imponer tasas al comercio, como en Sicilia, el Reino de Nápoles y otras principalidades inferiores; o indirectamente, al hacer más fácil a los asentamientos sin carta de poblamiento ni privilegios urbanos el establecimiento de mercados y ferias contra la oposición de las ciudades monopolizadoras ${ }^{19}$.

Unos costes de transacción más reducidos entre regiones políticamente definidas aumentaron la competencia entre ciudades. Un análisis de los mercados regionales de grano, que eran notoriamente susceptibles de elevados niveles de control político y manipulación, ha mostrado que la creciente competencia interna produjo un marcado aumento en la integración de los metcados después de mediados del siglo $\mathrm{XV}^{20}$; esto coincide cronológicamente con el auge de jerarquías urbanas más definidas. Una mayor integración mercantil explica tam-

19 EPSTEIN, S. R., «Regional fairs, institutional innovation and economic growth in Late Medieval Europe», Economic History Review, 2nd ser. 47, 1994, págs. 459-482; id, «Market structures» en CONNEJ.L, W. J. y ZORZI, A. (eds.), Florentine Tuscany: structures and practices of power, Cambridge, 1998; SAKELLARIOU, The Kingdom of Naples... caps. 4-5.

20 EPSTEIN, An island..., cap. 3; idem, «Market structures...».

Hitipania, LVIII/2, núm. 199 (1998) 417-438 
bién por qué las ciudades más afectadas fueron las de rango medio, cuya pérdida de independencia política y poder económico no fue compensada por mayores funciones administrativas, y las cuales en algunos casos -el ejemplo más conocido es la Toscana florentina - fueron las más afectadas por las políticas fiscales punitivas de las nuevas capitales regionales. Por contra, la presión sobre las ciudades menores tendió a relajarse, en parte por el decreciente poder de las ciudades en el nivel superior dentro de la jerarquía urbana, y en parte porque los nuevos gobernantes regionales las usaron para disminuir el poder de las mayores, otorgando a las ciudades pequeñas funciones administrativas y concediéndoles audiencia en sus conflictos con las ciudades ${ }^{21}$.

3. El tercer cambio importante provocado por la "crisis» fue territorial. Las diferencias territoriales aumentaron en relación con el alcance de la recuperación urbana y el crecimiento y con las características de la jerarquía urbana.

A la altura de comienzos del siglo XVI se distinguían tres pautas principales de urbanización. En primer lugar, un considerable número de regiones parece haber experimentado un período de estancamiento o incluso de declive. En ellas estaban buen parte de Italia central (Emilia-Romagna, Toscana, Umbria y las Marcas) y varias de las regiones meridionales más limitadas en tierras (Abruzzo Citra, Basilicata, Calabria Citra, Capitanata y el Principato Citra) ${ }^{22}$. En segundo lugat, varias regiones (incluidas algunas de las más urbanizadas antes de la peste) lograron recuperar los niveles de población urbana anteriores a la Peste Negra pero fueron incapaces de superarlos. Estas áreas incluían la llanura del Po (Lombardía y el Véneto), Sicilia y la Calabria meridional (Calabria Ultra) que quedó integrada en el hinterland de Messina. Por último, había unas pocas regiones que experimentaron un fuerte auge de la urbanización. Se trata del Piamonte (gracias al auge de Tutín como capital regional y a las ciudades "protoindustriales» de Casale Monferrato y Mondovi), el Lazio (gracias al crecimiento de Roma), Terra di Lavoro (gracias al auge de Nápoles) y Abbruzzo Citra (por el crecimiento de la ciudad industrial y comercial de l'A quila).

Esta pauta indica que las regiones con tasas de urbanización decrecientes o estancadas superaron con creces a las que experimentaron un incremento neto en la proporción de habitantes urbanos, y refuerza la evidencia circunstancial previamente citada que sugiere que hacia 1500 la urbanización general en Italia no había aumentado e incluso puede haber sufrido un pequeño descenso. Más aún, los incrementos mayores y más rápidos en la urbanización ocurrieron como un efecto del crecimiento de dos nuevas ciudades (amperiales», Roma y Nápoles. El crecimiento de Nápoles en particular elevó la tasa de urbanización

21 CimTtoj,ni, G., «Centri minori e città fra Medioevo e Rinascimento» en Colle di Val d'Elsa: diocesi e città fra '500 e' '600, Castelfiorentino, 1995, págs. 11-37; EPSTEIN, «Cities, regiones...», idem. "Town and country in Late Medieval Italy: Economic and institutional aspects», Economic History Review, 2nd ser, 46, 1993, pp. 453-477.

22 GINATEMPO, M., «Dietro un'eclissi: considerazioni sulle città minori dell'Italia centrales en GENSINI, S. (ed.), Italia, 1350-1450: tra crisi e trafformazione, Pistoia, 1993, págs. 35-76; SAKELLARIOU, The Kingdom of Naples..., cap. 2. 
de su región, Terra di Lavoro, hasta niveles apenas logrados en la Europa moderna, cercanos al 60 por ciento del total (Tabla 3). Por contra, el crecimiento urbano en el norte de Abbruzzi y Piamonte se debía más a un proceso de convergencia de regiones previamente poco urbanizadas en la media nacional. En estos dos últimos casos, el crecimiento urbano fue generado endógenamente, pero fue disparado por el acceso a mercados suprarregionales de materias primas industriales y textiles de bajo precio.

En conclusión, la urbanización estancada o en declive parece haber principalmente sido una consecuencia del tipo de estructura urbana existente antes de la Peste Negra. Hubo tres situaciones de declive:

a) la ciudad principal preexistente en la región sufrió un declive en sus funciones. Esto ocurrió en Toscana, donde Florencia perdió su predominio sobre el comercio de larga distancia en los mercados de la Italia meridional y se orientó a la sobreexplotación de su pequeño Estado regional, y en Emilia-Romagna, donde la anterior hegemonía económica de facto de Bolonia fue cuestionada por los nuevos principados encabezados por Ferrara, Parma y Piacenza;

b) una región con ciudades jurisdiccionalmente poderosas y fuerte competencia urbana por recursos que carecía de ciudad hegemónica. Esto creó lo que se conoce como «dilema del prisionero», en el que la estrategia dominante (o más valiosa) para dos ciudades consistía en actuar uegoístamente", por ejemplo no colaborando, a pesar de que el beneficio de esa acción sería inferior al de la cooperación; la colaboración quedaba impedida por los elevados costes de transacción que implicaba el cumplimiento de los acuerdos que comprometían a las dos partes. Este tipo de "fallo del mercado» sólo podía ser resuelto por un agente exterior que pudiera hacer cumplir las reglas aceptadas de común acuerdo entre las ciudades. En estas circunstancias, la ausencia de una ciudad dominante o un poder territorial fuerte que pudiera actuar para resolver conflictos intraurbanos colocaba a estas ciudades en gran desventaja en comparación con otras ciudades situadas en regiones políticamente más jerarquizadas. Estas condiciones negativas se daban en particular en Umbria y las Marcas, que se hallaban bajo la soberanía nominal papal y donde el Papado apuntalaba su débil autoridad consintiendo las reclamaciones de las élites urbanas de «independencia» jurisdiccional ${ }^{23}$;

c) una región con ciudades jurisdiccionalmente débiles que carecía de una ciudad hegemónica, y que fue llevada por la crisis demográfica a la agricultura extensiva y el pastoreo asociado con la baja densidad de población. Este proceso se adapta al caso de las regiones desurbanizadas del sur ${ }^{24}$.

23 GINATEMPO, «Dietro un'eclissi..»; idem, "Gerarchie demiche...».

24 SAKELJARIOU, The Kingdom of Naples..., cap. 2.

Hippania, LVIII/2, núm. 199 (1998) 417-438 
¿Cuáles fueron las implicaciones a largo plazo de las diferencias en las jerarquías urbanas señaladas? Las jerarquías carecen, sin duda, de significado por sí solas; son constructos artificiales cuya función es la de identificar fuerzas económicas y demográficas subyacentes que son muy dificiles de observar de manera independiente. La descripción de las jerarquías es simplemente una actividad preliminar necesaria para plantear las cuestiones de interés: ¿Qué procesos «reales» reflejaban las diferencias en la estructura urbana? ¿Estaban las diferentes jerarquías urbanas asociadas con pautas diferentes de actividad económica dentro de las regiones y es posible, por consiguiente, servirse de ellas para inferir un crecimiento económico más rápido o más lento?, o, por decirlo de manera algo distinta, ¿qué pauta de incentivos económicos refleja una jerarquía urbana dada?

Estas preguntas han provocado una vasta literatura pero muy poco acuerdo general, dando pie a un creciente escepticismo acerca del valor predictivo del modelo de los «lugares centrales». No obstante, muchos de estos problemas han aparecido debido a que se ha dado priotidad a la «forma» del mercado sobre su "contenido». Ha habido una tendencia a inferir una estructura de mercado y una pauta de incentivos directamente de una jerarquía urbana sin analizar con suficiente intensidad qué es lo que dichas estructuras y pautas eran de hecho ${ }^{25}$. Por consiguiente, la respuesta a las preguntas de arriba requiere una observación más detallada de las estructuras de mercado subyacentes y sus cambios en el tiempo. Esto nos devuelve a mi anterior sugerencia de observar la "crisis" bajomedieval como una "crisis de integración», y la expansión de la soberanía de los Estados terriroriales como una significativa fuerza que provocó un proceso generalizado de integración regional. Debido a que la integración de orientación estatal fue resistida por poderosas fuerzas locales, que se negaron a perder económicamente por el descenso de los aranceles y políticamente por la pérdida de derechos jurisdiccionales sobre la producción y el co-

25 La cuestión de la uprimacía metropolitana es un buen ejemplo. El hecho de que los historadores económicos británicos consideren la primacía de Londres una valiosa fuente de crecimiento desequilibrado (WRIGLEY, E. A., «A simple model of London's importance in changing english society and economy, 1650-1750r, Past and Present, 37, 1967, págs. 4470 thay traducción al castellano, en WRIGLEY, E. A., Gentes, ciudades y riquexa: la transformación de la sociedad tradicional, Barcelona, 1991]) mientras que los historiadores del área del mediterráneo juzgan que el predominio de Nápoles y Madrid ahogó la economia de sus paises (MARN, B., «Naples: capital of the Enlightenment), en CLARK, P. y LEPETTT, B. (eds.), Capital cities and their binterlands in Earty Modern Europe, Aldershot, 1996, págs. 143-167; RINGROSE, D., Madrid and the spanish economy, 1560-1850, Berkeley, 1983 [hay traducción al castellano, Madrid, 1980]) es motivo de desconcierto. La diferencia entre las dos situaciones puede ser probablemente explicada en referencia a las estructuras de mercado más amplias en las que estas capitales se hallaban inmersas. Este punto emerge con fuerza de las conclusiones de debates recientes sobre la primacía madtileña; véase HERNANZ ELVIRA, J. L., «Town and countryside in the Crown of Castile. Madrid and its linterland in the Early Modem Periods en NI NEILL, R. (ed.), Toun and country in western Europe from 1500 to 1939, Leicester, 1996, págs. 55-83. 
mercio, la expansión de la soberanía estatal y por consiguiente la intensidad de la integración económica interna fue muy variable de territorio a territorio en relación con el equilibrio de poder predominante. En consecuencia, el proceso de formación estatal bajomedieval dio pie a diferentes estructuras de mercado y diferentes pautas de incentivos que condujeron a las economías regionales hacia diferentes vías de crecimiento económico.

Para comprender lo que esto significa en la práctica es posible comparar la integración impulsada por el Estado en tres esferas particulares: el mercado urbano de cereales para el consumo; la proliferación de instituciones de mercado en el campo; y el desarrollo de la manufactura rural (o eprotoindustria)).

Durante la Baja Edad Media, las políticas de abastecimiento de alimentos orquestadas por ciudades y Estados entraron en creciente conflicto ${ }^{26}$, al aumentar la integración de las ciudades en los sistemas regionales y suprarregionales de producción y distribución que se hallaban más bien fuera de su control y que trataban de reclamar para sí los Estados. Sin embargo, la mayor parte de las ciudades continuaron imponiendo el acceso privilegiado al abastecimiento de alimentos en sus hinterlands a través de derechos jurisdiccionales. En consecuencia, fueron capaces de responder a descensos imprevistos de productos alimenticios proclamando leyes que aplicaban la autarquía local. Esta pauta de comportamiento, que se hallaba extendida por la mayor parte de las ciudades europeas premodernas, era completamente racional mientras existieran expectativas razonables de que todas las ciudades dentro de un área de abastecimiento dada actuaran de la misma manera. El objetivo de estos controles era doble: proporcionar a los habitantes de las ciudades productos alimenticios a bajo precio, y reducir las violentas fluctuaciones (la volatilidad) de los precios, que también dañaba a los consumidores. En realidad, no obstante, este sistema de vetos de comercio recíproco creaba un «Dilema del Prisionero» cuyas consecuencias eran las contrarias a las intenciones de las ciudades.

Así, en la Toscana renacentista, las barreras con y sin arancel erigidas por ciudades particulares de hecho elevaban el coste del grano para los consumidores urbanos y aumentaban los costes de recolección de la información sobre los mercados. A su vez, mayores costes de información aumentaban la volatilidad de los precios. El aumento de la volatilidad tenía lugar en dos fases. En la primeta fase, debido a que las restricciones en materia de información y en flujos de mercado retrasaban los abastecimientos externos, los administradores reaccionaban a las escaseces locales con adquisiciones de la oferta local para genetar stocks amortiguadores. Esta actividad elevaba los precios drásticamente, debido también a que los consumidores seguían la dirección marcada por la ciudad de acumular stocks en prevención de la escasez. Al comenzar a llegar las importaciones meses más tarde, los precios caían en picado al modificar los consumidores sus expectativas y dilapidar las reservas acumuladas. Las autoridades se veían obligadas también a vender sus reservas, a menudo por debajo del coste, lo cual hacía que los precios descendieran aún más. La suma total de

26 Véase EPSTEIN, «Market structures...» para una discusión de la literatura.

Hìpania, LVIII/2, núm. 199 (1998) 417-438 
estas acciones daba lugar a un drástico aumento de la volatilidad de los precios en lugar de su reducción, que era la finalidad de los controles urbanos sobre el comercio.

A pesar de que una elevada volatilidad y la creciente competencia urbana afectaba al bienestar de los consumidores en las ciudades, este Dilema del Prisionero podía prevalecer mientras ninguna ciudad se decantara por el cambio en los patámetros institucionales dominantes por medio de una abolición unilateral de los controles sobre el comercio. Dada la inestabilidad inherente a este descoordinado sistema de abastecimiento urbano de alimentos, estaba claramente en el interés tanto de los poderes territoriales como en el de los consumidores urbanos el establecimiento de una mayor cooperación entre ciudades. Por tanto, en principio, la centralización política debería haber permitido el desarrollo de mercados más coordinados y eficientes, pues la autoridad central, respaldada con el apoyo popular, hacía cumplir las reglas del libre comercio entre ciudades. En la práctica, intereses poderosos segaban a menudo los beneficios de la integración en términos de precios más bajos y estables de productos alimenticios por medio del veto a la reforma institucional. Las circunstancias políticas de la reforma eran por consiguiente de la mayor importancia.

El equilibrio perverso de autarquía mutua sólo podía ser roto por una fuerza exterior - un príncipe soberano o un parlamento autocrático- que pudiera comprometer con suficiente credibilidad a las ciudades a cooperar en un área de libre comercio por medio del castigo a los infractores de las normas. Esto ocurrió de manera muy efectiva en Sicilia, donde tras una exitosa invasión en la década de 1390, los nuevos gobernantes aragoneses liberalizaron el mercado interno de grano y las exportaciones. La reforma fue posible porque los oponentes potenciales o bien eran en el caso de la aristocracia inusualmente débiles o bien se hallaban como las ciudades mayores bajo el control directo del monarca. En el reino de Nápoles, en contraste, el mayor poder de la aristocracia feudal y el menor contrapeso proporcionado por el sector urbano bajo control regio hizo inviable a los monarcas bajomedievales y altomodernos la introducción y el mantenimiento del comercio libre. Los aragoneses respondieron a este impasse por medio de una oleada de privilegios económicos y fiscales a la capital, Nápoles, que dejó su mercado de grano, en solitario en todo el reino, libre de todo tipo de impuestos arancelarios. Una oferta de alimentos baratos y con regularidad se halla entre los secretos del extraordinario crecimiento de Nápoles en la Baja Edad Media y la temprana Edad Moderna. Por el contrario, las barreras al comercio que siguieron aplicándose en otras ciudades italianas meridionales contribuyeron a su limitado desarrollo ${ }^{27}$. En Toscana, finalmente, el ascenso de Florencia a la hegemonía en el curso del final del siglo XIV y en el $\mathrm{XV}$ tuvo escaso impacto sobre los mercados regionales de grano. A pesar de que a las ciudades dependientes no les estaba ya permitido detener los envíos de grano con dirección a Florencia, en lo demás podían continuar sus políticas

27 DE VRIES, European urbanization... pág. 112 se plantea la cuestión de «por qué las ciudades de rango intermedio no eran más gxandes» en el Reino de Nápoles.

Hispania, LVII/2, num. 199 (1998) 417-438 
proteccionistas tradicionales. La oportunidad de coordinar el abastecimiento de grano urbano más eficientemente sólo emergió hacia 1550 bajo el duque Cosme I, que introdujo una política de abastecimiento regional unificada y abolió los vetos al comercio mutuo entre ciudades, dando lugar al colapso de la volatilidad de los precios del grano.

Las diferentes estructuras de poder dentro de los estados también afectaron al desarrollo de infraestructuras comerciales más eficientes en el campo. El considerable aumento en el número de ferias periódicas a lo largo de Europa occidental y centro-oriental en un tiempo de drástico declive demográfico puede contarse como uno de los desarrollos institucionales y económicos más chocante de la Baja Edad Media. Sin embargo, aunque las nuevas ferias respondían a necesidades económicas reales de sistemas de distribución más integrados y complejos, eran fieramente resistidas por los centros mercantiles existentes, la mayor parte de ellos ciudades bien establecidas económica y politicamente que temían la competencia comercial y la pérdida de ingresos de sus portazgos aduaneros. Las nuevas ferias requerían por consiguiente apoyo politico específico para ser establecidas; en la medida en que los estados centralizadores podían servirse de concesiones de ferias rurales para desafiar las reclamaciones jurisdiccionales de las ciudades, las ferias eran concedidas con gusto. Por otro lado, los poderes territoriales no tenían por qué ignorar las objeciones de algunos de sus súbditos poderosos; por consiguiente, las nuevas ferias eran en muy contadas ocasiones instituidas dentro del área de control jurisdiccional directo de las ciudades. En su lugar, se desartollaron en los intersticios jurisdiccionales de los Estados, en comunidades que habían por algún motivo escapado al control urbano o que eran geográficamente periféricas, con el resultado de que sobre el mapa de las nuevas ferias los espacios en blanco se corresponderían prácticamente con las jurisdicciones urbanas ${ }^{28}$.

Argumentos similares funcionan en relación con el desarrollo de la manufactura en el campo. Como el auge de las ferias, el despliegue de la protoindustria rural (en particular textil) es un fenómeno a menudo reseñado de la Baja Edad Media. Las industrias rurales emergieron en respuesta a tres factores. Por el lado de la demanda, la redistribución de ingresos disponibles de los señores a los campesinos y asalariados ocasionada por la peste estimuló la demanda de productos de consumo de bajo precio. En el lado de la oferta, el declive de la demanda de productos alimehticios básicos redujo el coste de oportunidad del empleo industrial subsidiario en áreas peor dotadas para la producción agrícola; los costes de transacción en descenso hicieron más fácil el comercio de bienes baratos a más larga distancia. Pero la mano de obra barata y la baja materia prima y costes de transacción no eran suficientes para que emergiera una industria rural exitosa; tenía que superarse también la oposición presentada por los productores urbanos. De la misma manera que la centralización estatal estimuló el desarrollo de ferias rurales, el crecimiento del Estado facilitó el desafio por parte de las nuevas industrias a los monopolios tradicionales de los

28 Véase EPSTEIN, «Regional fairs...».

Ilippania, LVIJI/2, núm. 199 (1998) 417-438 
artesanos urbanos sobre la producción en el campo. En este caso también, entonces, pautas de formación estatal tuvieron un impacto directo sobre el desatrollo económico de las regiones ${ }^{29}$.

En suma, las instituciones políticas regionales podían proveer de un marco de abastecimiento de grano barato y estable, de sistemas de distribución eficientes y de una industria rural dinámica; de manera indirecta, podian estimular la especialización, el crecimiento económico, y en consecuencia también la urbanización. Pero no tenían por qué hacerlo. Los desarrollos urbanos en la Italia bajomedieval sugieren que la urbanización posterior a 1500 tequería tres condiciones para tener éxito: primero, la presencia de una ciudad con dominio regional sobre funciones administrativas o económicas; segundo, el acceso a mercados suprarregionales de productos y servicios; y tercero, una integración jurisdiccional efectiva que redujera las barretas formales e informales a la producción y el comercio. Las diferencias urbanas y económicas regionales surgieron durante la Baja Edad Media de diferentes combinaciones de estos tres factores.

\section{$\mathbf{V}$}

La evidencia a escala regional que he tratado de presentar prueba más allá de toda razonable duda que las características institucionales de las ciudades desempeñaron un papel secundario en los resultados de la "crisis». Su papel fue esencialmente indirecto, y fue en su mayor parte negativo, expresándose en intentos por parte de intereses urbanos atrincherados de resistir de diversas maneras, obstruir y desviar los intentos de los poderes territoriales de extender la soberanía sobre sus derechos jurisdiccionales y fiscales. Donde, por el contrario, el poder consistía en elites de una ciudad libres de controles institucionales y equilibrios, como fue en gran medida el caso de la Toscana florentina, dichas elites tendrían muchas más oportunidades de captar la mayor parte de los beneficios de la integración política, con setios costes para la economía regional ${ }^{30}$.

Los rasgos institucionales de las ciudades fueron por consiguiente uno de los diversos elementos que dieton a los Estados regionales bajomedievales su forma definitiva y que contribuyeron a la integración territorial. No obstante, los superiores derechos jurisdiccionales sobre el campo que poseín las ciudades del norte de Italia no fueron, al fin y al cabo, la causa última de ninguna de las persistentes diferencias económicas entre el Norte y el Sur: ni fueron una duradera fuente del crecimiento urbano en el Norte, como durante un tiempo se pensó, ni fueron una continuada fuente de opresión rural y explotación y,

29 Idem. «Town and country...».

30 Ibidem; idem «Stato terntoriale ed economia regionale nella Toscana del Quattrocento» en FUBINI, R. (ed.), Istituzioni, cultura ed arte in Toscana nell'età di Lorenzo il Magnifico, Pisa, 1996, III, pp, 869-890.

Hispunia, LVIII/2, núm. 199 (1998) 417-438 
por medio de éstas, de una transición retrasada o «fracasada» al capitalismo moderno, como ha sido defendido más recientemente.

Lo que la evidencia en cambio señala es la extraordinaria diversidad y amplitud de la experiencia regional, que ninguna división geográfica ni tasgo institucional puede captar de manera adecuada. Esto sugiere una reflexión final. Italia no constituía un sistema «unificado», ni económica ni institucionalmente: ninguna narrativa unificadora, ningún rasgo definitorio singular puede dar cuenta de la experiencia del país de una forma distintiva respecto de otras trayectorias nacionales europeas. $\mathrm{Si}$ acaso, el origen de la más permanente especificidad de Italia fue también la fuente de su diversidad y división regional: verbigracia, las oportunidades de engrandecimiento que se les presentaban por estar en el cruce de vías comerciales, políticas y religiosas del Mediterráneo y Eutopa occidental. Por desgracia, el cosmopolitismo profundamente asentado del país fue olvidado en nombre de las narrativas nacionales del siglo XIX y del dualismo epistemológico al que dieron lugat.

Traducción de Vanesa Rufete 